\title{
Detection of Anti-Trypanosoma Cruzi Antibodies among Donors at A Blood Bank from Southern Mexico, Using an Iron Superoxide Dismutase Excreted (Fe-Sode) as Antigen
}

\author{
Concha-Valdez $\mathrm{F}^{1,2}$, Marín $\mathrm{C}^{1}$, Cañas-Ruíz $\mathrm{R}^{1}$, Sosa-Matú $\mathrm{C}^{3}$, Escobedo-Ortegón $\mathrm{J}^{2}$, Martín-Montes $\mathrm{A}^{1}$, \\ Francisco Olmo ${ }^{1}$ and Sánchez-Moreno $\mathrm{M}^{* 1}$
}

${ }^{1}$ Department of Parasitology, Institute for Biosanitary Research, Hospitals University of Granada, Granada, Spain ${ }^{2}$ Regional Research Center "Dr. Hideyo Noguchi”, Autonomous University of Yucatan, Mexico

${ }^{3}$ Blood bank of Regional General Hospital 17 of the Mexican Social Security Institute of Cancun Q. Roo, Mexico

*Corresponding author: Sánchez-Moreno M, Department of Parasitology, Institute for Biosanitary Research, Hospitals University of Granada, Granada, Spain, Fax: +34 958 243174, Tel: +34 958 248886, E-mail: msanchem@ugr.es

Citation: Concha-Valdez F, Marín C, Cañas-Ruíz R, Sosa-Matú C, Escobedo-Ortegón J, et al. (2017) Detection of Anti-Trypanosoma Cruzi Antibodies among Donors at A Blood Bank from Southern Mexico, Using an Iron Superoxide Dismutase Excreted (Fe-Sode) as Antigen. J Immunol Infect Dis 4(1): 105

Received Date: April 27, 2017 Accepted Date: June 14, 2017 Published Date: June 16, 2017

\begin{abstract}
Objectives: Trypanosoma cruzi, the causal agent of Chagas disease in humans, is a widely spread protozoan in Latin America. Chronically infected people are asymptomatic during an indeterminate stage but can represent a significant risk of transmission due to blood donations and organ transplants. Blood transfusion is recognized as the second most important path for transmitting of Chagas disease; in addition, it can be recognized as the main important route in industrialized non-endemic countries. The aim of the present work was to detect anti-T. cruzi antibodies in blood donors in Cancun, Quintana Roo, Mexico.

Design and Methods: We implemented 5 serological diagnostic tests in 969 individuals; two in-house ELISAs were used: a wholeparasite lysate (ELISA-H) and other using the semi-purified iron-superoxide dismutase excreted by T. cruzi (ELISA-FeSODe); Western blot against the same antigen (WB-FeSODe), Indirect Immunofluorescence (IIF), and one commercial test.

Results: The serological test results showed a seroprevalence range of low to high: from $5(0.51 \%)$ donors by the commercial ELISA (Chagas ELISA IgG+IgM) and 19(1.96\%) by IIF, 43(4.43\%) detected by ELISA-H; 115 (11.86\%) by WB-FeSODe and 148 (15.27\%) as the highest seroprevalence by ELISA-FeSODe.

Conclusion: The evaluation of the reliability of the ELISA FeSODe in the diagnosis of Chagas disease showed a sensitivity of $99.13 \%$ and specificity of $96.01 \%$. We identified a high prevalence of T. cruzi seropositive donors, suggesting a high risk of contamination through blood transfusion. The excellent sensitivity and good specificity of FeSODe antigen for the detection of anti-T. cruzi antibodies in donors lead us to confirm that the serological test performed with FeSODe would be a helpful test for screening in blood banks as confirmatory test for Chagas disease.
\end{abstract}

Keywords: Blood donors; Chagas disease; Diagnosis; Iron superoxide dismutase excreted; Trypanosoma cruzi

\section{Introduction}

In 2016 the World Health Organization established June $14^{\text {th }}$ as the World Blood Donor day. The campaign's objective is to foment voluntary unpaid blood donations, which need to be increased rapidly in more than half the world's countries in order to ensure a reliable supply of safe blood for patients whose life depend on it [1]. During recent decades, efforts towards blood safety have been focused in preventing viral infections, however, as it has been demonstrated that other pathogens can also be transmitted by transfusion [2]. One of these is Trypanosoma cruzi, causal agent of Chagas disease (CD), which is estimated to affect about 7 million people worldwide and, in Latin America 25 million people live in risk areas. Only in 2008, 10,000 deaths related to CD were reported $[3,4]$.

The parasite can be transmitted by vectors, through the bite of a hematophagous bug of the Triatominae family that leaves an open wound where the parasites (located in the insect's faeces) can enter. Also, other mechanisms include as blood transfusion, organ transplants, congenital transmission, and accidental ingestion of the insect in food or drinks and by laboratory accidents [4]. Blood transfusion is recognized as the second most common way of acquiring the infection in the developed countries [4-8]. Previously, 
the CD had been related to people who lived in poor rural areas, but migration has brought about changes in such a way that this pathology is now found in big cities of Latin America, and other continents [9]. Because the disease spends most of the time in asymptomatic phase, a carrier of T. cruzi can be a potentially contaminated blood potential donor till 60-65 years according to each country's legislation $[10,11]$.

In addition, with the exception of blood derivatives (coagulation factors, albumin, etc.), all blood components (erythrocytes, leukocytes, platelets, etc.) may be infective [12].

The role played by the Pan American Health Organization (PAHO) in controlling the CD transmission by blood transfusion is well recognized. With their support, the health ministries in countries forming part of the Southern Cone Initiative, in July 1991, recognized the huge magnitude of the problem, and committed themselves to the eradication of the vector (Triatoma infestans) in the region, and also to eliminate the transmission of T. cruzi by strengthening of the blood banks through the effective control of the donors $[10,13]$.

Mexico was one of the last countries of Latin America in implementing a grand-scale programme against the T. cruzi transmission. In 1998, the serology in the blood banks was made mandatory; but only in endemic areas. In 2000, a national policy in CD control matter was approved; and the Health Ministry approved a law concerning anti-T. cruzi antibody detection in all national territory, which was modified in 2012 [11,14,15]. Various studies have been made in Mexico, all in order to search the prevalence of antibodies anti-T. cruzi in blood donors [14,16,17]. Guzmán, et al. using as a screening test for the indirect hemagglutination (IHA) and as confirmatory the indirect immunofluorescence (IIF), determined a national prevalence of $1.5 \%$. Furthermore, the country received a stimated 850,000 donations a year, of which 12,750 were infected by T. cruz. Therefore, $15 \%$ of the receptors, namely, 1,912 people were potentially infected with T. cruzi $[14,15]$.

In our study, the prevalence of anti-T. cruzi antibodies was stimated in donors of the blood bank in a hospital in southern Mexico. Five serology tests were used, according to the WHO recommendation of using more than just one serology procedure to reduce misdiagnosis [18]. We employed an in-house ELISA and WB, which both use as antigen iron superoxide dismutase protein excreted, FeSODe of T. cruzi, that in previous studies have shown a high immunogenicity, sensibility and specificity [19-21].

Super Oxide Dismutases (SOD) are a group of antioxidant metalo-enzymes that play a key role in the defence against super oxide radicals. As host cells trigger an oxidant response as defense against infections, trypanosomatids depend on them for survival, and thus, they are a virulent factor [22].

\section{Materials and Methods}

\section{Study area}

The study was carried out in Quintana Roo state, it's located on the Yucatan Peninsula, bordering the state of Yucatan to the northwest, west state Campeche, Gulf of Mexico to the north and Belize and Guatemala to the south and east is washed by the water of the Caribbean Sea. A warm humid climate with a temperature range of $24-28^{\circ} \mathrm{C}$ and a precipitation range of $0-1300 \mathrm{~mm}$. It has a population of 1,325,578 inhabitants (National Institute of Statistics and Geography) (Figure 1).

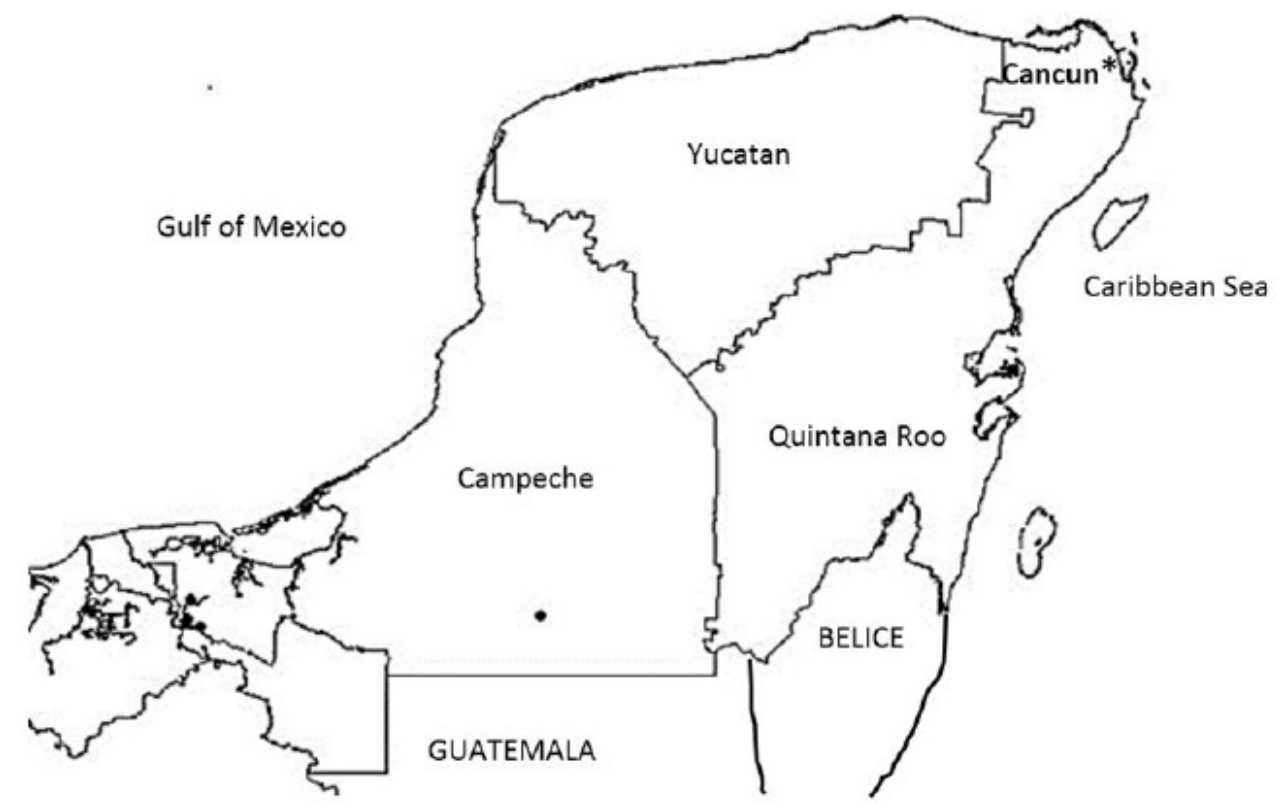

Figure 1: Geographical location of Cancun on the Yucatan Peninsula 


\section{Donor selection}

Sera from 969 blood donors, who looked apparently healthy, were included. Blood samples were obtained in the Regional General Hospital Zone \#17 of the Mexican Social Security Institute (IMSS) in Cancun, Quintana Roo, Mexico. Among the selection criteria included people of both sexes, aged from 18 to 65 years old who weighed more than $50 \mathrm{~kg}$ and were seronegative to: Hepatitis B Virus (HBV), Hepatitis C Virus (HCV), Brucella abortus (BRA), Treponema pallidum, Plasmodium sp, the surface antigen of the Hepatitis B virus (HBsAg), and the human acquired immunodeficiency virus (HIV). Almong excluded donors have been included receptors for any transplantation, pregnant women, or women during lactancy according to NOM -253-SSA2 2012. All blood donors will agreed to participate to the study by signing a letter of consent approved ethic protocol by the Ethics Committee for Research of the University of Granada (Spain).

\section{Serum samples}

Samples were obtained from June 2012 to February 2013 and collected from the cubital vein through the Vacutainer system (Vacutainer BD, Franklin Lakes, NJ, USA). Each serum was separated by centrifugation (1,200 g for 10 min) and aliquoted into 1.5 $\mathrm{mL}$ tubes and frozen at $-20{ }^{\circ} \mathrm{C}$ until use. Also were included 10 sera positive controls, these sera were diagnosed by the Regional Blood Transfusion Centre (CRTS) in Malaga, Spain, and the State Blood Transfusion Center in Cancun (CETS).

\section{Parasites and culture}

Epimastigote forms of T. cruzi of the strain H4 (MHOM/MX/2001/H4), isolated from a human patient with severe pathology in the state of Yucatan, Mexico, were grown routinely in axenic medium trypanosome liquid (MTL) medium (Gibco, Alcobendas, Madrid, Spain) supplemented with $10 \%$ heat-inactivated foetal bovine serum (FBS) at $56{ }^{\circ} \mathrm{C}$ in Falcon flasks [23]. The parasite culture (in the exponential growth phase) was concentrated by centrifugation at $600 \mathrm{~g}$ for $10 \mathrm{~min}$.

\section{Whole-parasite lysate}

To obtain whole-parasite extract or a homogenate fraction ( $\mathrm{H}$ fraction), the T. cruzi $\mathrm{H} 4$ parasite culture was recovered as described above. The cell pellet was then washed twice with phosphate-buffered saline (PBS) and resuspended in ice-cold sodium Tris / HCl ethylenediaminetetraacetic acid / $\mathrm{NaOH}$ (0.25 M sucrose, 25mM Tris/HCl, 1mM EDTA, pH 7.8; buffer sodium chloride-TrisEDTA [STE]). The whole-parasite extract or fraction $\mathrm{H}$ was obtained following the method described elsewhere [19,20].

\section{Extraction and purification of the excreted FeSOD}

In order to extract and purify the excreted SOD (SODe), we harvested the T. cruzi H4 cell pellet in the exponential phase. The pellet was washed twice in MTL medium without serum, and the number of cells counted in a haemocytometric chamber. The cells were distributed into aliquots of $5 \times 10^{9}$ parasites/ $\mathrm{ml}$ and in grown in MTL medium not enriched with FBS, as described elsewhere [19]. Briefly, the resulting culture supernatant was enriched in the excreted proteins by precipitation with 35-85\% ammonium sulphate. The resulting precipitate was finally redissolved in $2.5 \mathrm{ml}$ of distilled water and desalted by chromatography in a Sephadex G-25 column (PD 10 column; GE Healthcare, Barcelona, Spain), previously equilibrated with $25 \mathrm{ml}$ of distilled water, bringing it to a final volume of $3.5 \mathrm{ml}$ (fraction FeSODe for T. cruzi). The protein content was determined using the Sigma Bradford test, based on the Bradford method (Sigma Immunochemical, St Louis, Missouri USA), with bovine serum albumin (BSA) as a standard [24]. The FeSODe obtained thus was used as antigen in the ELISA and Western blot tests, for the diagnoses of the serum samples analysed in this study against T. cruzi.

\section{Serological tests}

ELISA assays: Two ELISA assays were performed with different antigen fractions, one with the homogenated fraction (ELISA-H) and the second with FeSODe (ELISA-SODe). The total $\mathrm{H}$ fraction and semipurified SODe fractions, at a concentration of 5 and $1.5 \mathrm{mg}$, respectively, were coated on to a 96-well polystyrene plate (Nunc, Penfield, NY, USA) in carbonate buffer ( $\mathrm{pH} 9.6$ ) for $2 \mathrm{~h}$ at $37^{\circ} \mathrm{C}$. The assay was performed at a serum dilution of 1:200, following the methodology described elsewhere [25]. Absorbance was read at $492 \mathrm{~nm}$ in a Sunrise microplate reader (Tecan, Las Rozas, Madrid, Spain). All the samples were analysed in triplicate in polystyrene microtitre plates. This is a quantitative test for which mean and standard deviation (SD) of the optical densities of the negative control sera were used to calculate the cut-off value $($ mean $+3 \times \mathrm{SD})$.

Western blot assay (WB): For the Western blot assay, the antigen fraction of FeSODe (at a concentration $1.5 \mathrm{mg}$ of protein) was run on IEF 3-9 gels and afterwards transferred to nitrocellulose membrane (Hybond C Extra; GE Healthcare, Barcelona, Spain) using the PhastTransfer kit, as described by the manufacturer (PhastSystem handbook). The Western blot qualitative method was carried out as described elsewhere [26].

Indirect Immunofluorescence (IIF): All samples were subjected to IIF, epimastigotes of the strain of T. cruzi H4 were centrifuged at $1,500 \mathrm{~g}$ for $10 \mathrm{~min}$ and then washed three times with PBS and suspended at a final concentration of $5 \times 10^{6}$ parasites $/ \mathrm{ml}$. 10 $\mu \mathrm{l}$ of the epimastigotes suspension were plated in each well of the slides for immunofluorescence (Grace Bio-Labs, Bend, OR, USA) and were hold for few minutes to allow the evaporation of the buffer. Then, the cells were fixed with pure acetone at room 
temperature. Finally staining was performed, with this aim, the wells were first incubated for $30 \mathrm{~min}$ at room temperature with 1:32 previously diluted sera from patients. Control sera (positive and negative) were also included in the test. The slides were washed three times with PBS and then were incubated for another $30 \mathrm{~min}$ at room temperature with the secondary antibody (anti-human IgG conjugated with fluorescein 5-isothiocyanate FITC; Sigma-Aldrich, St Louis, Missouri, USA) at a dilution of 1:100 in PBS containing Evans Blue (0.003\%). Then, the slides were washed 3 times again with PBS and finally buffered glycerol was added (9 volumes of glycerol, 1 volume of PBS) and the coverslips were deposited above to proceed with quantitative examination under a fluorescence microscope MOTIC BA410 (Motic, Barcelona, Spain) [27,28].

Commercial test: Chagas ELISA IgG + IgM (Vircell, Granada, Spain) is an indirect immunoenzymatic assay for determination of IgG + IgM antibodies against T. cruzi in human serum or plasma. The method is based on the reaction of antibodies in the sample with the antigen bound to the surface of the polystyrene wells in the microplate. Unbound immunoglobulins are eliminated in the washing process. The anti-human conjugated with peroxidase reacts with the antigen-antibody complex and then reacts with the substrate tetramethylbenzidine (TMB) to give a blue color reaction, which changes to yellow upon addition of the stop-reaction solution.

\section{Statistical study}

Data were recorded on an Excel spread sheet (Microsoft, Redmond, WA, USA), and statistical analysis performed by using SPSS Statistics (V. 17) software (IBM, NY, USA). Also statistical studies based on contingency tables (prevalence) were conducted, together with the $\chi^{2}$ test of the relationship between variables.

The sensitivity and specificity of the serological tests were calculated as in Thrusfield [29].

\section{Results}

A total of 969 blood donors were evaluated for the presence of anti-T. cruzi antibodies using five serological tests: ELISA-H, ELISAFeSODe, WB-FeSODe, IIF, and a commercial ELISA test. These donors were between 18 and 59 years of age, with an average age of 34.1. Among them, 126 were men and 843 were women, for a ratio of 1:6.7. All donors had tested negative for HBV, HCV, BRA, HBsAg, HIV, Treponema pallidum, Plasmodium spp., and Leishmania braziliensis, according to the criteria of the NOM-253SSA2-2012.

The prevalence found using the 5 serological tests was, from lowest to highest, as follows: five donors $(0.51 \%)$ were positive for the presence of anti-T. cruzi antibodies with the commercial test, 19 (1.96\%) by IIF, 43 (4.43\%) were detected by ELISA-H, 115 (11.86\%) by WB-FeSODe, and 148 (15.27\%) by ELISA-FeSODe (Figure 2).

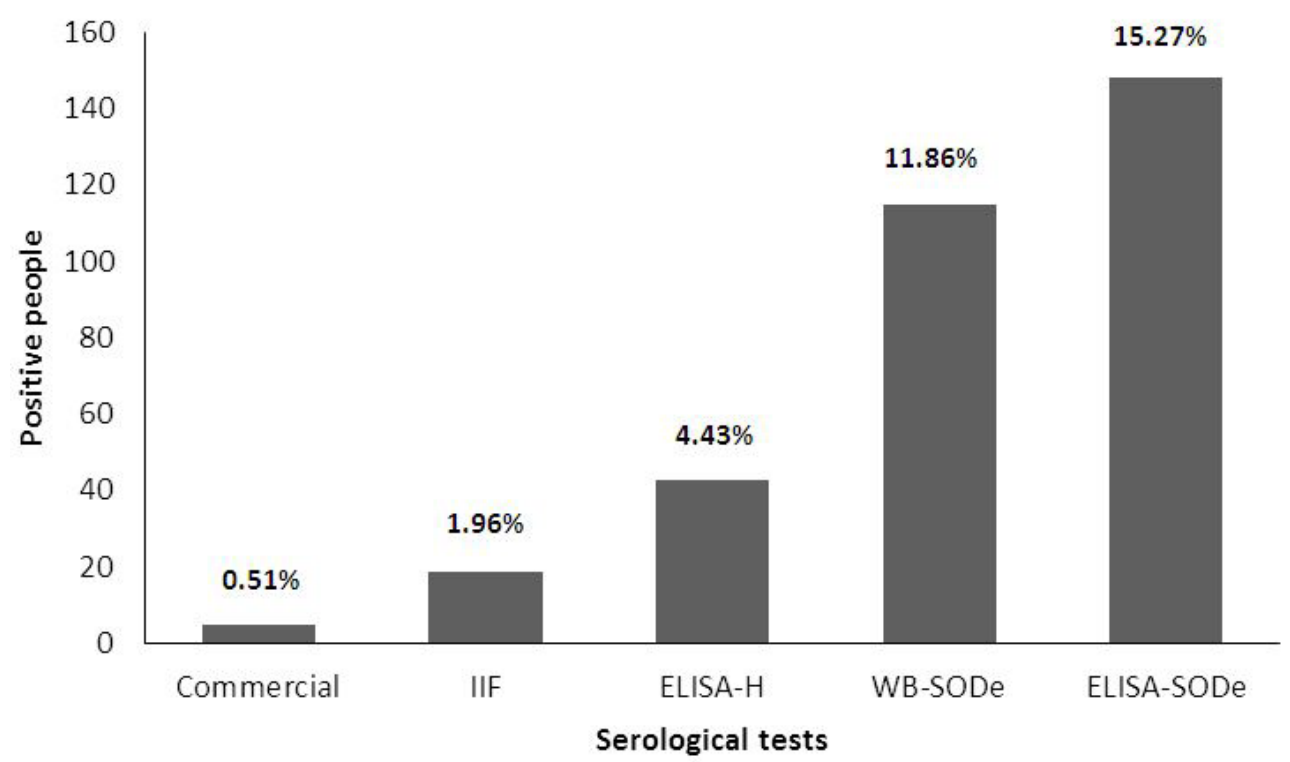

Figure 2: Prevalence of Chagas disease determined in blood donors that give positives value of antibodies against $T$. cruzi $\mathrm{H} 4$ strain by five different serological tests

Only 148 sera that were positive to ELISA-FeSODe underwent testing to confirm the positive diagnose by WB-FeSODe, using as antigen FeSODe as described above (Figure 3). False positives by ELISA test are possible due to crosses with other trypanosomatid protozoans, as well as other species of the genus Trypanosoma and other species belonging to the genus Leishmania. However, in previous studies, we have shown that FeSODe is species-specific and, for that reason, does not show cross reactions with other trypanosomatids or with other pathogenic organisms $[20,30]$. It was also shown that by the homemade serological tests for detecting a much larger number of positive samples rather than the commercial test could. 


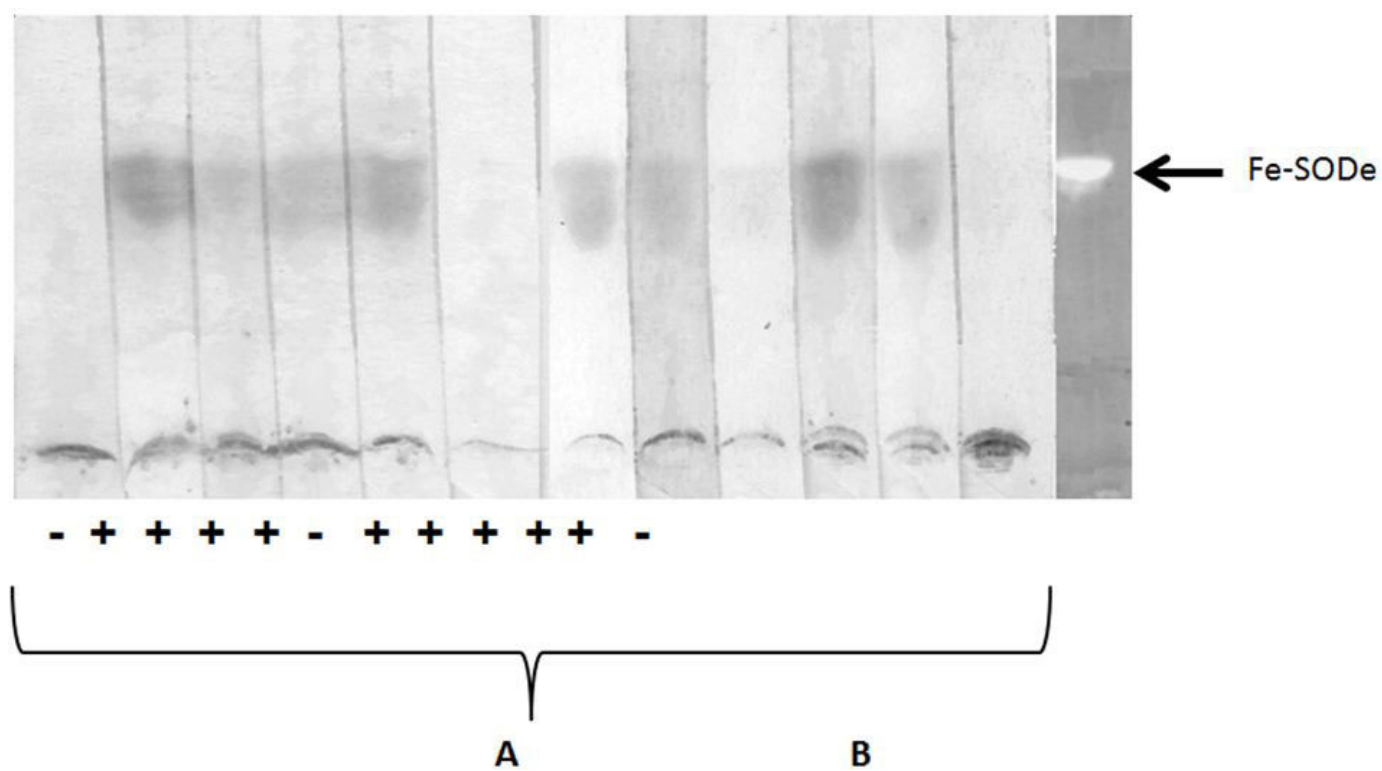

Figure 3: Western blot of some positive and negative sera from blood bank donors Cancun, Mexico, against the SODe antigen from T. cruzi $\mathrm{H} 4$ strain epimastigotes (A) and, SODe activity in isoelectrofocus and staining following the technique of Beyer and Fridovich; (B) Isoelectric point of $\mathrm{Fe}-\mathrm{SODe}=3.9$

Regarding the reliability of homemade serological tests homemade for detecting anti-T. cruzi antibodies compared with IIF as the reference test the ELISA-FeSODe had the highest sensitivity and specificity (100\% and $86.42 \%$, respectively), but with very low concordance (0.200) (Table 1). Second, the WB-FeSODe test had a sensitivity of $73.68 \%$ and a specificity of $89.36 \%$. When comparing the ELISA-FeSODe was compared with WB-FeSODe, as if it were a reference test, sensitivity was $99.13 \%$, specificity $96.01 \%$, and the level of concordance 0.846 . This level improved when used the WB-FeSODe was used as the reference test, not when the IIF was used, because this test has very low sensitivity.

\begin{tabular}{|c|c|c|c|c|c|}
\hline & IIF/ELISA-H ${ }^{*}$ & $\begin{array}{l}\text { IIF/ELISA- } \\
\text { SODe }^{*}\end{array}$ & $\begin{array}{l}\text { IIF/WB- } \\
\text { SODe }^{*}\end{array}$ & $\mathrm{IIF} / \mathrm{CT}^{\star}$ & $\begin{array}{c}\text { WB/ELISA- } \\
\text { SODe }^{\mathrm{a}}\end{array}$ \\
\hline Sensitivity & $52.63 \%$ & $100 \%$ & $73.68 \%$ & $21.05 \%$ & $99.13 \%$ \\
\hline Specificity & $96.52 \%$ & $86.42 \%$ & $89.36 \%$ & $99.89 \%$ & $96.01 \%$ \\
\hline PPV & $23.25 \%$ & $12.84 \%$ & $12.17 \%$ & $80.00 \%$ & $77.00 \%$ \\
\hline NPV & $99.02 \%$ & $100 \%$ & $99.41 \%$ & $98.44 \%$ & $99.87 \%$ \\
\hline Kappa index & 0.3033 & 0.200 & 0.190 & 0.332 & 0.846 \\
\hline
\end{tabular}

${ }^{\star}$ Calculation made take IIF as reference test; ${ }^{a}$ Calculation made take WB as reference test; CT: Commercial test; PPV: Positive Predictable Value; NPV: Negative Predictable Value

Table 1: Evaluation the Reliability of the In-House Serological Tests

Our results demonstrate the reliability to use the ELISA-FeSODe, plus all the features such as easy implementation and low cost compared to other diagnostic tests. For all these reasons, we propose this test for the diagnosis of CD.

\section{Discussion}

Although Mexico was one of the last countries in Latin America to implement a program to prevent the transmission of CD, it has progressed over the last few decades. Hence, the Mexican Government has approved national laws, to avoid infection by blood transfusion [11]. The rate of spreading of infectious diseases by transfusion steadily decreases over time in most countries, in parallel to increased screening coverage. This has been demonstrated since in 1999, when it was assumed that 722 people had been infected through blood transfusions, while in 2002 this number was reduced by half, although that the screening of $100 \%$ of the donors is mandatory only for endemic areas of the country [5,31].

Because CD remains asymptomatic (chronic phase) for years or decades, the infected individual can become a potential donor for a long period of time, and according to the laws of some countries until 60-65 years old [10,11]. Since infected subjects generate an immune response and serum antibodies specific to the infection, serological techniques constitute the main approach to the diagnosis of chronic CD, becoming essential in screening donors for blood banks. In addition, it has been shown that commercial serological tests using antigens from other countries are less sensitive than assays using native antigens or lack the precision suggested by the manufacturer, therefore we used a strain of T. cruzi isolated in the region $[23,32,33]$.

Novelo, et al. included 55 of the 71 hospitals of the IMSS that have blood bank, and reported a national prevalence of $0.406 \%$ using HAI and ELISA-Chagascreen (using antigens of strains mainly isolated in South America), where banks of Poza Rica, Cancun 
and Villahermosa were the presented the highest seropositivity, with $3.118 \%, 1.986 \%$ and $1.796 \%$, respectively [33,34]. The doubly positive sera found (ELISA-FeSODe and WB-FeSODe) in the present study gave a seroprevalence of $11.76 \%$ (114 donors), if it is considered that $20 \%$ of the units contaminated transmitted the infection by transfusion ( 23 donors) [35]. Besides this high prevalence, this fact shows that $\mathrm{CD}$ is no longer only confined to rural areas, due to high migration from the rural zone to some cities that are the tourist and industrial centers of the country, presenting an alarming scenario, since people infected with T. cruzi could be donating blood without undergoing a screening test because now they are in areas of Mexico not considered endemic $[14,34]$.

Regarding the serological tests used, the commercial test showed less sensitivity. As has been demonstrated the use of local strains of the parasite, in this case a strain isolated from the region, increased sensitivity in the detection of patients with CD in Mexico $[32,33]$. In addition to the commonly applied techniques for the diagnosis of CD in Mexico are the IHA and IIF it is known that the sensitivity and specificity of these techniques are very low compared to techniques such as ELISA [14,16,17,32,34]. Therefore, it is necessary to design more accurate of diagnostic tests and based on native antigens rather than the ones currently used in blood banks in Mexico.

In the present study, a high prevalence of $T$. cruzi seropositive donors was identified, suggesting a high risk of contamination through blood transfusions, as well as the transmission of Chagas disease despite the serologic screening performed in the blood banks. Also, it is known that endemic areas have spread by migration from rural areas to cities, causing that $\mathrm{CD}$ carrier to be donors. For this reason it is essential to carry out the serological screening in $100 \%$ of blood donors nationwide to prevent the spread of this disease. Because the state of Quintana Roo is considered to have a strong migratory attraction from rural areas, CD is being transmitted through blood transfusion [14].

\section{Conclusion}

We identified a high prevalence of T. cruzi seropositive donors, suggesting a high risk of contamination through blood transfusion. The results in the present study allow us to propose the use of the FeSODe as antigen for the diagnose of the Chagas disease due to its remarkable sensitivity and specificity, detecting the antibodies against T. cruzi in the different blood donors by using serological tests as ELISA and WB.

\section{Acknowledgment}

We also appreciate the commercial Vircell (Spain) for their kind donation of tests kits.

\section{Funding}

This work was supported by Proyectos Precompetitivos del Plan Propio 2011 of the University of Granada (Spain). Fanny ConchaValdez is grateful for a PROMEP Grant from the Secretary of Public Education of Mexico.

\section{Ethical approval}

The study design was approved by the Ethics Committee for Research of the University of Granada (Spain).

\section{References}

1. WHO (2016) World blood donor day 2016. Blood connects us all. Geneva, Switzerland.

2. Schmidt M, Geilenkeuser WJ, Sireis W, Seifried E, Hourfar K (2014) Emerging pathogens-How safe is blood? Transfus Med Hemother 41: 10-7.

3. Pereira PC, Navarro EC (2013) Challenges and perspectives of Chagas disease: a review. J Venom Anim Toxins Incl Trop Dis 19: 34.

4. WHO (2015) Chagas disease (American trypanosomiasis). World Health Organization fact sheet No 340. March 2015, Geneva, Switzerland.

5. Schmunis GA (1999) Prevention of transfusional Trypanosoma cruzi infection in Latin America. Mem Inst Oswaldo Cruz 94: 93-101.

6. Grant IH, Gold JW, Wittner M, Tanowitz HB, Nathan C, et al. (1989) Transfusion-associated acute Chagas disease acquired in the United States. Ann Intern Med 111: 849-51.

7. Villalba R, Fornés G, Alvarez MA, Román J, Rubio V, et al. (1992) Acute Chagas'disease in a recipient of a bone marrow transplant in Spain: case report. Clin Infect Dis 14: 594-5.

8. Pereira BI, Nazareth C, Malcata L, Alves H, Fernández JR, et al. (2011) Parasitic infections transmitted by blood transfusion What is the Risk in Non-Endemic Countries? (Infecções parasitárias transmitidas por tranfusão de sangue. Qual o risco nos países não endémicos?) Acta Med Port 24: 897-906.

9. Castro E (2009) Chagas' disease: lessons from routine donation testing. Transf Med 19: 16-23.

10. Moraes-Souza H (1999) Chagas infection transmission control: Situation of transfusional transmission in Brazil and other countries of Latin America. Mem Inst Oswaldo Cruz 94: 419-23.

11. Official Mexican Standard (1994) NOM-253-SSA1-2012. For the disposal of human blood and its components for therapeutic purposes (modifies NOM-003SSA2-1993, published July 1994). Off J Federation. Ministry of Health, Mexico. (Norma Oficial Mexicana. NOM-253-SSA1-2012. Para la disposición de sangre humana y sus componentes con fines terapéuticos (modifica a la NOM-003-SSA2-1993, publicada en julio de 1994). Diario oficial de la federación. Secretaría de Salud, México).

12. Wendel S (2010) Transfusion transmitted Chagas disease: Is it reallly under control? Acta Trop 115: 28-34.

13. Dias JCP, Schofield CJ (1997) Transfusional transmission control of Chagas' disease in the Southern Cone Iniciative. Rev Soc Bras Med Trop 31: 373-83. 
14. Guzmán BC, García GL, Floriani VJ, Guerrero MS, Torres CM, et al. (1998) Risk of transmission of Trypanosoma cruzi by blood transfusion in Mexico. (Riesgo de transmisión de Trypanosoma cruzi por transfusión de sangre en México). Rev Panam Salud Pública 4: 94-8.

15. Guzmán BC (2001) Epidemiology of Chagas disease in Mexico: an update. Trends in Parasitol 17: 372-6.

16. Sánchez GM, Barnabé C, Guégan JF, Tibayrenc M, Velásquez-Rojas M, et al. (2002) High prevalence anti-Trypanosoma cruzi antibodies, among blood donors in the State of Puebla, a non-endemic area of Mexico. Mem Inst Oswaldo Cruz 97: 947-52.

17. Ramos LA, Ramírez SM, González HC, Luis RJ, López-Monteon A, et al. (2006) Prevalence of Trypanosoma cruzi antibodies in IMSS blood donors, Orizaba, Veracruz, Mexico. (Prevalencia de anticuerpos contra Trypanosoma cruzi en donadores de sangre del IMSS, Orizaba, Veracruz, México). Salud Púb Mex 48: 13-21.

18. Camargo ME, Segura EL, Kagan IG, Pacheco SJM, Carvalheiro JR, et al. (1987) Standardization of the serological diagnosis of Chagas disease in the Americas: evaluation of three years of collaboration. (Normalización del diagnóstico serológico de la enfermedad de Chagas en las Américas: evaluación de tres años de colaboración). Bol Oficina Sanit Panam 102: 449-63.

19. López AL, Villagrán E, Briceño KA, de Diego JA, Hernández-Montiel HL, et al. (2012) Trypanosoma cruzi: seroprevalence detection in suburban population of Santiago de Querétaro (Mexico). Scientific World J 2012: 914129.

20. Marín SC, Longoni S, Urbano J, Minaya G, Mateo H, et al. (2009) Enzyme-linked immunosorbent assay for superoxide dismutase-excreted antigen in diagnosis of sylvatis and andean cutaneous leishmaniasis of Perú. Am J Trop Med Hyg 80: 55-60.

21. Marín C, Concha-Valdez F, Cañas R, Gutiérrez-Sánchez R, Sánchez-Moreno M, et al. (2014) Anti-Trypanosoma cruzi antibody detection in eastern Andalusia (Spain). Trans R Soc Trop Med Hyg 108: 165-72.

22. Paramchuk WJ, Ismail SO, Bhatia A, Gedamu L (1997) Cloning, characterization and overexpression of two iron superoxide dismutase cDNAs from Leishmania chagasi: role in pathogenesis. Mol Biochem Parasitol 90: 203-21.

23. Barrera-Pérez MA, Rodríguez-Félix ME, Guzmán-Marín E, Zavala-Velázquez J, Dumonteil E, et al. (2001) Biological behaviour of three strains of Trypanosoma cruzi from Yucatan, Mexico. Rev Biomed 12: 224-30.

24. Bradford MM (1976) A rapid and sensitive method for the quantitation of microquantities of protein-dye binding. Anal Biochem $72: 248-54$.

25. Mateo H, Sánchez MM, Marín C (2010) Enzyme-linked immunosornent assay with purified Trypanosoma cruzi excreted superoxide dismutase. Clin Biochem 43: 1257-64.

26. Villagrán ME, Marín C, Rodríguez-Gonzalez I, De Diego JA, Sánchez-Moreno M, et al. (2005) Use of an iron superoxide dismutase excreted by Trypanosoma cruzi in the diagnosis of Chagas disease: Seroprevalence in rural ones of the state of Queretaro, Mexico. Am J Trop Med Hyg 73: 510-6.

27. Olivera Mar A, Guillén Ortega F, Cruz Vidal S, Hernández-Becerril N, Pérez Galdamez E, et al. (2006) Serological and parasitological screenig of Trypanosoma cruzi infection in mothers and newborns living in two chagasic areas of Mexico. Arch Med Res 37: 774-7.

28. Marín C, Hitos AB, Rodriguez-González I, Dolletb M, Sánchez-Morenoa M, et al. (2004) Phytomonas iron superoxide dismutase: a possible molecular marker. FEMS Microbiol Lett 234: 69-74.

29. Thrusfield M (2005) Veterinary Epidemiology ( $4^{\text {th }}$ Edn) Oxford-Blackwell Science, UK.

30. Longoni SS, Marín C, Sauri-Arceo CH, López-Cespedes A, Rodríguez-Vivas RI, et al. (2011) An iron-superoxide dismutase antigen-based serological screening of dogs indicates their potencial role in the transmission of Cutaneous Leishmaniasis and Trypanosomiasis in Yucatan, Mexico. Vector Borne Zoonotic Dis 11: $815-21$.

31. Schmunis GA, Cruz JR (2005) Safety of the blood supply in Latin America. Clin Microbiol Ver 18: 12-29.

32. Sánchez B, Monteón V, Reyes PA, Espinoza B (2001) Standarization of micro-enzyme-linked immunosorbent assay (ELISA) and Western blot for detection of Trypanosoma cruzi antibodies using extracts from mexican strains as antigens. Arch Med Res 32: 382-8.

33. Kirchhoff LV, Paredes P, Lomelí-Guerrero A, Paredes-Espinoza M, Ron-Guerrero CS, et al. (2006) Transfusion-associated Chagas disease (American trypanosomiasis) in Mexico: implications for transfusion medicine in United States. Tranfusion 46: 298-304.

34. Novelo GA, Benitez AG, Peña BA, Galván-CG, Morales RA, et al. (2010) Detection of Trypanosoma cruzi In blood donors (Detección de Trypanosoma cruzi en donadores de sangre). Rev Med Inst Mex Seguro Soc 48: 139-44.

35. Schmunis GA, Zicker F, Pinheiro F, Brandling-Bennett D (1998) Risk for transfusion-transmitted infectious disease in Central and South America. Emerg Infect Dis 4: 5-11.

36. Beyer WF, Fridovich I (1987) Assaying for superoxide dismutase activity: some large consequences of minor changes in conditions. Anal Biochem 161: 559-66.

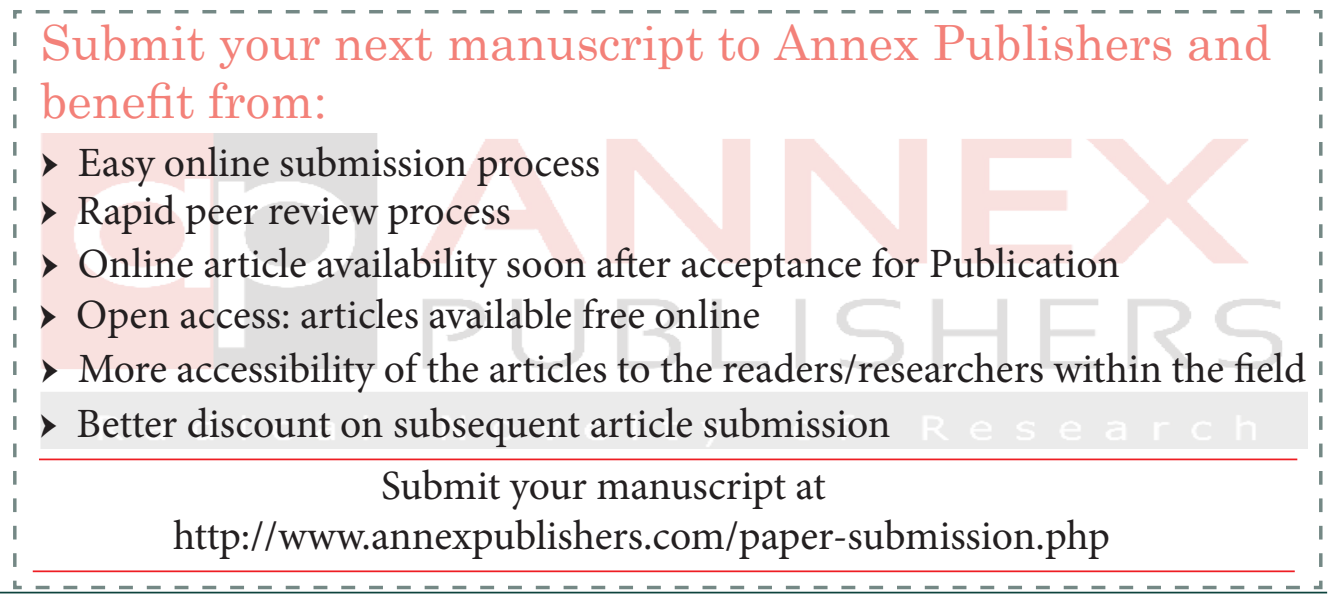

